\title{
Corrigendum: The miR-363-GATA6-Lgr5 pathway is critical for colorectal tumourigenesis
}

Shinnosuke Tsuji, Yoshihiro Kawasaki, Shiori Furukawa, Kenzui Taniue, Tomoatsu Hayashi, Masumi Okuno, Masaya Hiyoshi, Joji Kitayama \& Tetsu Akiyama

Nature Communications 5:3150 doi: 10.1038/ncomms4150 (2014); Published 23 Jan 2014; Updated 22 May 2014

In the original version of this Article, the image in the left panel of Fig. 5e was inadvertently duplicated from Fig. 6e. The error was also present in the full blot for Fig. 5e presented in Supplementary Fig. 3. The correct versions of Fig. 5 and Supplementary Fig. 3 appear below.
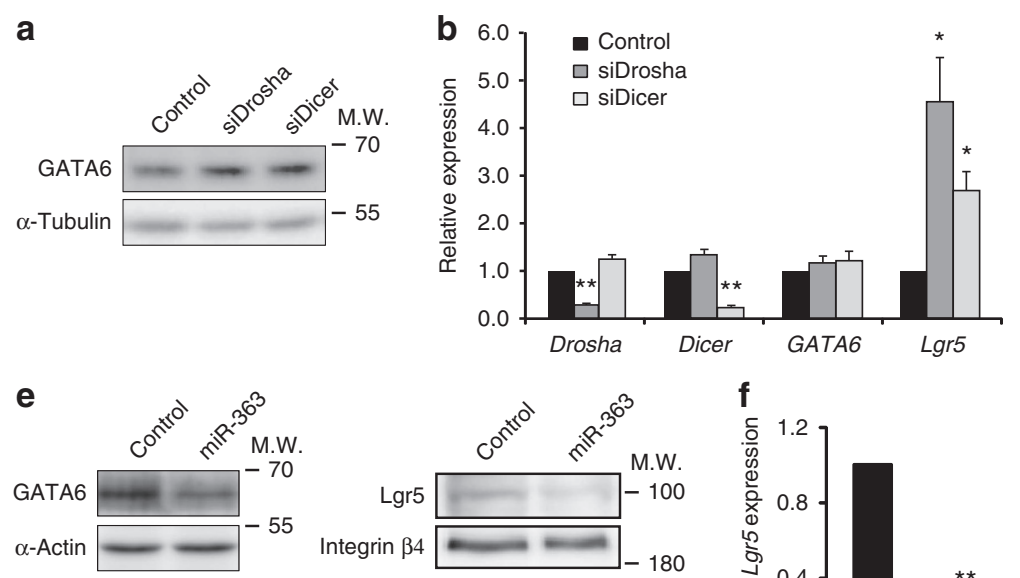

h

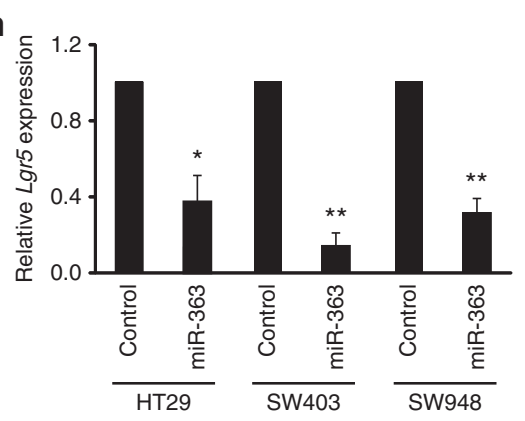

c
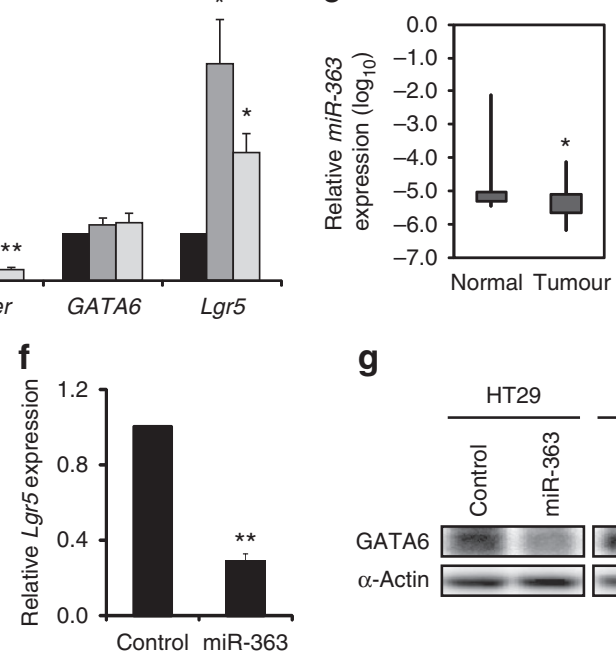

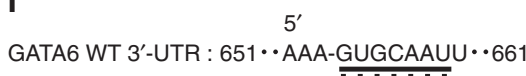
miR-363 sequence: • U UGG-CACGUUAA 3' GATA6 Mut 3'-UTR : $651 \cdot \cdot$ CAA-AAUCCACU $\cdot 661$ g
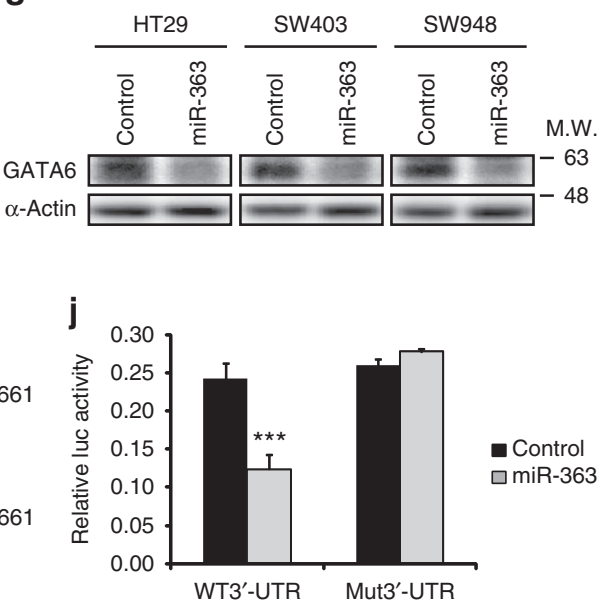

Figure 5 


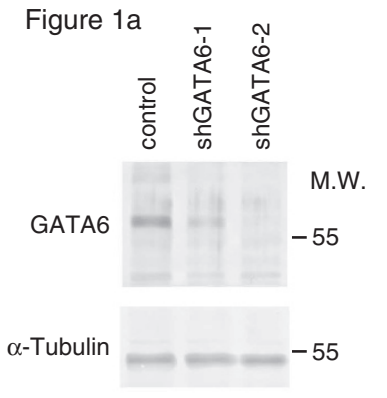

Figure $3 b$

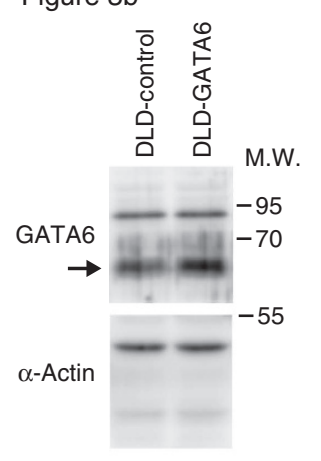

Figure 5a

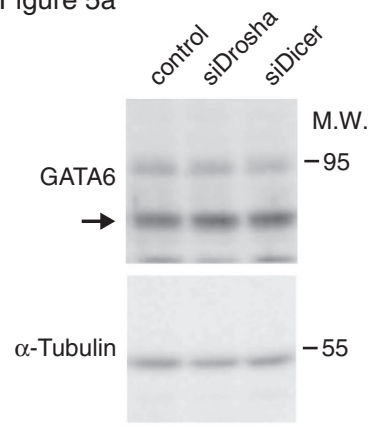

Figure $4 b$

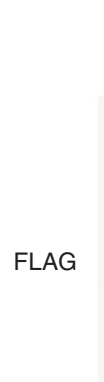

웜

Figure $5 e$

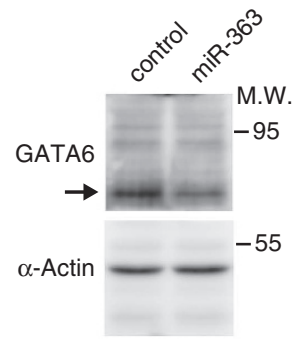

$-35$

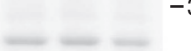

Figure 1c
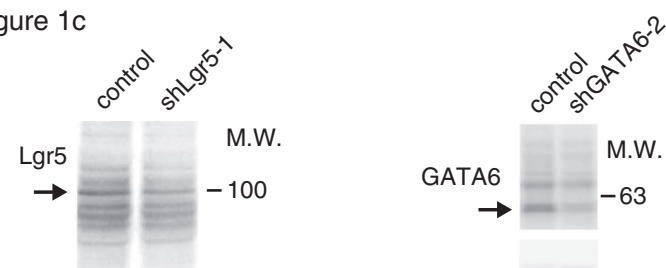

$\alpha$-Tubulin

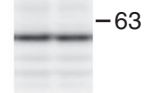

$\alpha$-Tubulin $=-63$

Figure 4c

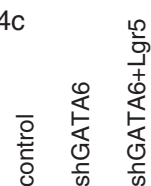

M.W.

$-180$

$-100$

FLAG

$-63$
Figure 4i

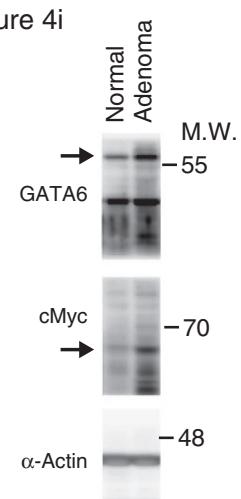

Figure $5 g$
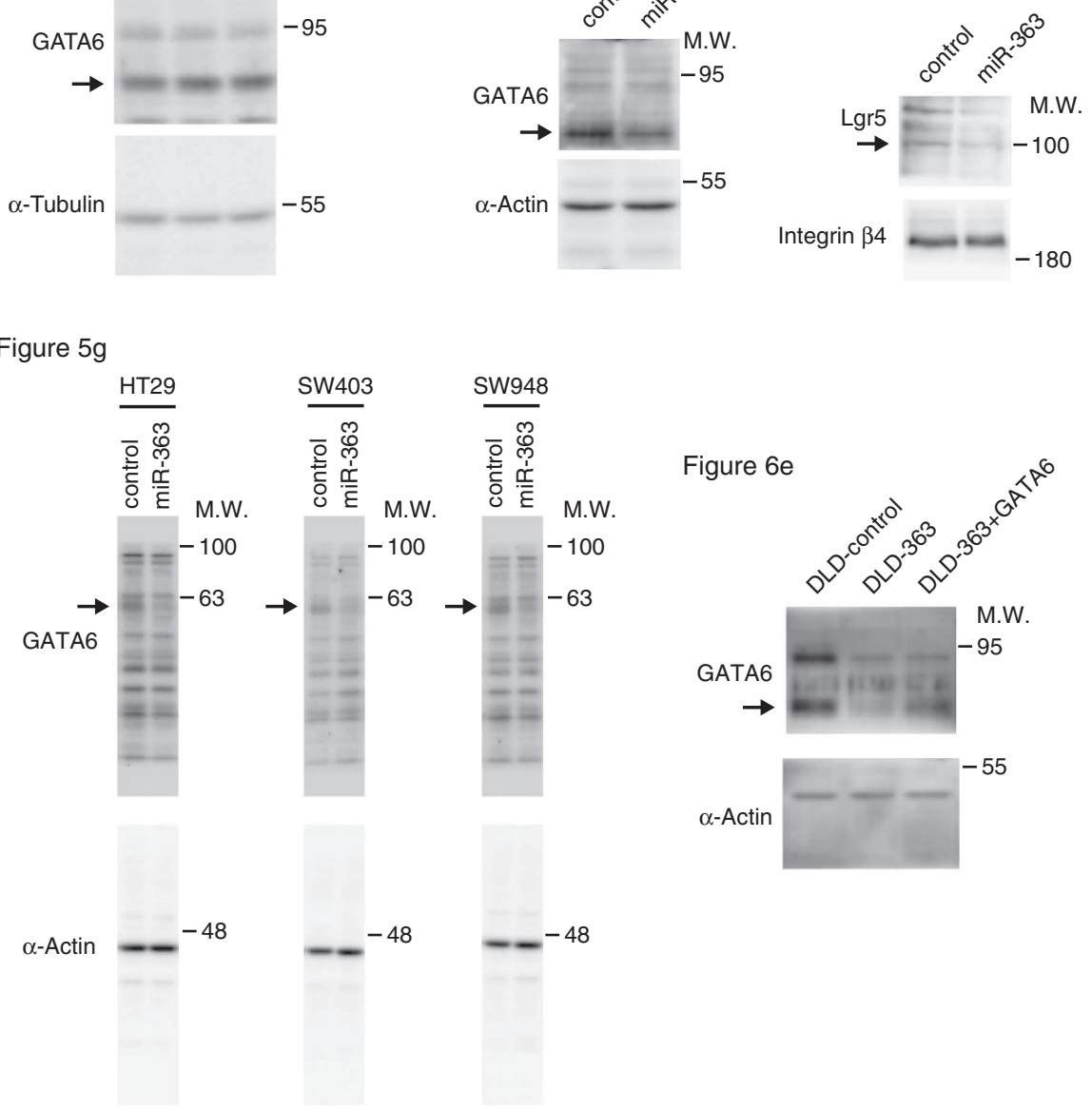

Figure 6a

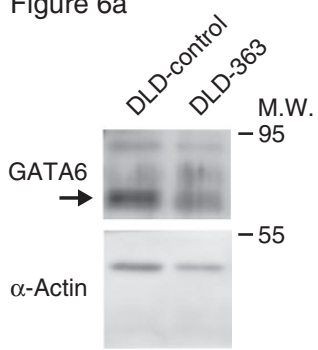

Figure 6g

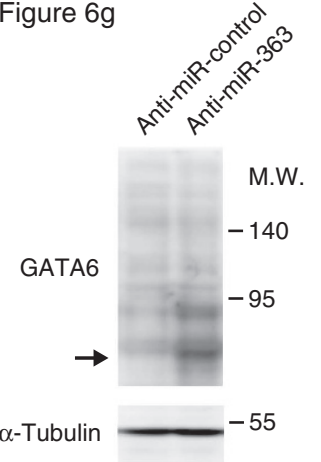

